2017 Global Fashion Management Conference at Vienna Proceedings: 230-234 (July 2017) https://doi.org/10.15444/GFMC2017.03.06.03

\title{
ARE FASHION CITIES REALLY FASHION CITIES? AN ANALYSIS ON CITY BRAND ASSOCIATIONS
}

\author{
Diletta Acuti, University of Pisa, Italy ${ }^{1)}$ \\ Valentina Mazzoli, University of Pisa, Italy ${ }^{2)}$ \\ Raffaele Donvito, University of Florence, Italy ${ }^{3)}$ \\ Priscilla Chan, Manchester Metropolitan University, $\mathrm{UK}^{4)}$
}

\begin{abstract}
This paper aims to monitor brand image of two important fashion cities on social media (Instagram). Through a content analysis of pictures and texts authors attempt to identify the main associations that various actors have of London and Florence, both traditionally strictly related to the fashion system. As recent literature has argued for brands or products, even for places and cities (Gilboa et al. 2015), it is important to monitor the perceived city brand image resulting from the overall online experience (Choi et al. 2007), especially on social media. Indeed, it is demonstrated that word of mouth on social media is able to strongly affect users' perceptions (Gretzel, Yuan, and Fosenmaier, 2000), thus contributing at the construction of the city brand image. This paper is one of the first one that applies content analysis on Instagram in city/place branding, where the core of communication is based on images. Therefore, differently from previous studies (Andéhn et al. 2014; De Moya and Jain, 2013), this work principally focuses on visual communication, as form of textual paralanguage communication (Luangrath, Peck, and Barger, 2016), for the construction of city image of London and Florence.
\end{abstract}

Keywords: city branding, place branding, city image, brand associations, word of mouth, Instagram, content analysis, fashion.

\section{INTRODUCTION}

Like the merchant city-states of Renaissance Italy, cities are today drivers of trade and industry in a globalized world (Gilboa et al., 2015).

In recent years, cities are searching new ways to promote themselves. Due to fast changes in technology and the continuous shift from local to a globalized environment, cities are forced to compete with each other in order to be an attractive destination, workplace, cultural rich place and much more (Kotler, 2002). Kavaratzis (2005) argues that the rising competition among cities might be seen as one of the effects of the globalization, which is visible in various forms and activity fields. So, many urban areas have turned to place branding strategies to develop strong competitive identities (Deffener and Liouris, 2005).

1) diletta.acuti@unifi.it

2) Contact author; valentina.mazzoli@unifi.it

3) raffaele.donvito@unifi.it

4) P.Chan@mmu.ac.uk 
The goal of place branding strategies is to build a symbolic, comprehensive image of a city, including its exclusive features and people, and subsequently communicate this image both locally and internationally. This type of integrated brand communication is a long-term strategy that needs to reflect a city's growth and development (Shoaib and Keivani, 2015) and can offer benefits to many stakeholders (Foroudi et al. 2016). This context has generated interest in studying place branding and it has become a widespread phenomenon throughout the world. Place branding literature includes studies of various entities such as cities, districts, regions, countries or groups of countries (Költringer and Dickinger, 2015).

City branding constitutes a sub-field of place branding and emphasizes the marketing and branding of cities to the residents (and potential residents) as a place to live, to businesses as a place to invest and to tourists as a place to visit (Merrilees, Miller and Herington, 2009). While the marketing of urban places has been practiced, at least, since the 19th century (Ward, 1998), cities increasingly tended to rely on marketing methods in the last four decades, when "competition for inward investment, tourism revenues and residents at various spatial scales intensified" (Kotler et al., 1999).

The initial research on city branding primarily concentrates on city brand image (Lynch, 1960); indeed, the existing city branding literature stresses a comparison of cities in terms of different brand image positioning, with an emphasis on the search for a differential, competitive position, which adds to the attractiveness of that city for its residents and others. In general, image is the mental picture that people hold about an object. Understanding these mental pictures is important because people's attitudes and actions toward the object (in this case a city) are highly conditioned by that object image (Kotler, 1997). Literature has tried to understand what are the components of these mental pictures; according to Gilboa et al. (2015), some associations were common to the majority of city branding studies - tourists, residents and investors - such as Culture, Entertainment, Infrastructure, Shopping Centers, Safety, Sport Facilities and Services. In particular, part of the literature has focused on the relevance of fashion in influencing a city image representation. According with Skivko (2016), fashion phenomenon creates and influences city branding, through which a city image is aimed at attracting visitors and consumers: in this way, fashion helps to build a certain identity for its followers through its trending and branding. However, this component needs to be observed not only as an isolated item: indeed, the city brand is part of a dense network of associations with various products, organizations, people, sites, artefacts and institutions that are originated (in the meaning proposed by Pike, 2011) in the city (Bellini and Pasquinelli, 2016).

The brand image can varies depending on stakeholders that may have different perceptions of the city (Virgo and de Chernatony, 2006) and cities can use branding as a way to unite their stakeholders around a new competitive identity and to communicate their message to target audiences (Gilboa et al., 2015). Indeed, city identity - that comprises the way a city is experienced by its various stakeholders, (residents, tourists and business people) - may be different from its image as perceived by its audiences. Indeed, city brand identity is a supply side construct that can be summarized by "the sum 
of its characteristic features and activities which differentiate it from other entities" (Klage, 1991, p.27). and it influences the demand side perspective, that is to say the city image (Merrilees et al. 2009). Consequently, image is the projection of the city identity in the minds of recipients (Kapferer, 1992). Therefore, the primary role of city branding is to clearly and consistently communicate the brand identity to multiple target audiences (Ruzzier and de Chernatony, 2013). Although these two constructs can be not aligned, place brands, as in other types of brands, should have the ability to communicate functional and symbolic meanings (Hankinson, 2006), which should relate to benefits, that is, the value offered.

However, place brands are not the only source of communication. Indeed, as Kavaratzis (2004) argues, identity can be conveyed through three levels. Particularly, primary communication includes different entities such as landscape, infrastructure, government structure and internal stakeholders' behavior. These features refer to first stakeholders' experience with places (Balmer and Gray, 1999). Secondary communications include public relations, visual identity system, promotions and advertising (Kerr and Oliver, 2014). Finally, tertiary communications include word of mouth (WOM). This latter form of communications is very important because is generated by different stakeholders: indeed, as the city branding literature recognizes, different actors may have different brand image associations (Fitchett, 2005; Friedman and Miles, 2002; Virgo and de Chernatony, 2006). This can be particularly relevant considering the influence of Internet-mediated communication as a form of user generated content that harness Electronic Word of Mouth (E-WOM). Indeed, as it happens for product or brands, even cities manifest themselves on social media as 'user-generated' becoming the result of how consumers, or users, project them in various social media platforms (Andéhn et al., 2014). This introduces a greater complexity in destination marketing, boosting the need to examine both textual and visual information provided to understand the complete structure of destination image formation in the online market space (Choi et al. 2007). Moreover, the Internet offers a great potential to influence consumers' perceived images (Gretzel, Yuan, and Fosenmaier, 2000). Consequently, image projection on the web is receiving greater attention from researchers and destination marketing practitioners (Choi et al. 2007).

In this perspective, this study follows this stream of research, by discovering the image formation on social media of two important fashion cities, London and Florence.

Authors consider that the great advantage of this work is based on the context of analysis. Indeed, this study is one of the first studies on city branding that focuses on Instagram, thus differentiating from previous studies that have concentrated on other social networks such as Twitter (Andéhn et al. 2014) or Facebook (De Moya and Jain, 2013). Various social media outlets have different operational logics, generating diverging forms of usergenerated brand content (Smith et al. 2012). Particularly, authors believe that Instagram has plural strengths. Firstly, it is one of the most used social media all over the world: it now has more than 400 million active users and over $60 \%$ of them log in daily, making it the second most engaged social network after Facebook (Brandwatch, 2016). Moreover, on Instagram, textual description and replies to followers are de-emphasized in favor of images (Marwick, 2015). This represents a relevant issue that differentiates Instagram 
from other social networks, considering that visual impressions are able to influence midand long- term human behavior (Pileliene and Grigaliunaite, 2016; Bergkvist, Eiderbäck and Palombo, 2012). Furthermore, visual communication is part of the textual paralanguage communication, and, as theorized by Luangrath, Peck and Barger (2016), the nature of these communications is under-investigated, even if it is growing in its importance, as the computer-mediated communication has become more prevalent. Additionally, the structure of posts provides a possibility to connect with other users, by including the name of another user in the form of a "mention" or by using specific tags called "hashtags" (words starting with a '\#' character), useful to denote topics on Instagram and to make posts more easily accessible by the public (Small, 2011).

In the following paragraphs, authors will discuss more in depth the objective of the paper and its research questions, the methodology applied and the expected results, considering also implications and future research directions.

\section{OBJECTIVE AND RESEARCH QUESTIONS}

Basing on tertiary communication (WOM) as important tool for building brand image (Kavaratsis, 2004), this paper aims to monitor brand image of two important fashion cities on social media (Instagram). To this regard, the purpose of this research is to understand how WOM affect the process of place branding, identifying the main associations of various actors related to London and Florence, both traditionally linked to the fashion system. Particularly, this paper focuses on fashion as a component of city image that contributes to build London and Florence image.

In this perspective, the research questions of the paper are the following:

RQ1a: Does social media contribute to the configuration of the image of traditional fashion cities?

RQ1b: If so, in which way does social media contribute to the configuration of the image of traditional fashion cities?

RQ2: What are the main association categories related to traditional fashion cities?

RQ3: How does fashion association relate to other association categories of city branding? RQ4: What are the roles of consumers, brands, institutions in the fashion city branding process in social media?

\section{METHODOLOGY}

This research will collect all posts related to the hashtag \#London and \#Florence, published on two different days for each city, during three different time slot (9-10 a.m., 2-3 p.m, 9-10 p.m.). One day of retrieving for each city is timely based in the period of fashion weeks (respectively, Pitti Uomo for Florence and London Fashion Week for London). The software $4 \mathrm{~K}$ Stogram will help the pictures download. Then, Authors will carry out a content analysis on posts retrieved basing on a protocol of analysis previously codified by the team of authors. Content analysis, especially text analysis, of usergenerated content is a frequently used approach in the marketing literature for mining consumers' perceptions from social media data (Culotta and Cutler, 2016; Fader and Winer, 2012). Based on this stream of empirical research authors will develop a content 
analysis of pictures (Riffe, Lacy, and Fico, 2005) with related comments and hashtag (hashtags will be analyzed through the software Nvivo) classifying them in different categories, namely historic building and heritage, cultural events, park and gardens, shopping (fashion), tourism facilities and infrastructure, entertainment and gaming, bird's eye scenic views, cuisine and dining, recreation/sport activities, people and local residents, and others (Choi, Lehto, and Morrison, 2007). "Others" will include all posts not directly related with the cities under analysis but included in the analysis because of the use of the hashtags under analysis just for increasing the post engagement. Images could be classified in more than one category, allowing researchers to identify connections between categories. This associative analysis will allow authors in discovering how cities are perceptually clustered by different types of stakeholders (Netzer et al. 2012; Archak et al. 2011).

Finally, posts will be classified in terms of posters' identity (consumers, brands, institutions and undetermined).

\section{EXPECTED RESULTS}

Authors expect to find positive associations to London and Florence image and think to point out the importance of fashion industries for these cities. According to Bellini and Pasquinelli (2016), authors suppose to find interesting links between fashion and others components of city branding, confirming city brand as part of a dense network of associations with various categories, products, organizations, people, sites, artefacts and institutions that are originated in the city.

Moreover, authors' expectation is a composite contribution to Instagram posts and, consequently, to cities image construction, that involves various consumers, brands and institutions.

\section{IMPLICATIONS AND FUTURE RESEARCH}

This study will be one of the first one that applies a content analysis on Instagram contents related to cities in order to retrieve the projection of different stakeholders on city image. This could lead to the development of a new methodology to monitor city brand image and the its alignment with the identity. Moreover, this methodology can be useful to assess also the positioning of the city brand in relationship with other cities according to the related brand associations retrieved from the user generated communication.

Future research could integrate simultaneously different social networks in assessing the city brand associations with the purpose to monitor the overall city brand image in the online context. Furthermore, future research could include different fashion cities in the analysis such as Milan, Paris and New York in order to clarify the role of fashion and fashion events in the city branding process.

\section{References}

References available upon request. 